\title{
Caring for People: a critical review of British Government policy for the community care of the mentally ill*
}

\author{
Frank Holloway, Consultant Psychiatrist, Camberwell Health Authority, \\ St Giles Hospital, St Giles Road, London SE5 7RN
}

The development of "community care' for the elderly, mentally ill, mentally handicapped and physically disabled has been Government policy in Britain since the 1950s. Problems with implementation of this policy led the Audit Commission (1986) to conclude that "the one option that is not tenable is to do nothing about present financial, organisational and staffing arrangements". Sir Roy Griffiths was commissioned to review "the way funds are used to support community care policy ...". Radical solutions were proposed and subsequently incorporated in the Government White Paper Caring for People (Department of Health, 1989a). However, two very signifcant measures were not accepted: the 'ring-fencing' of community care monies and the creation of a ministerial post within the Department of Health with specific responsibility for community care.

Caring for People attempts to provide a framework for community care in Britain during "the 1990 s and beyond", and will affect the clinical practice of all psychiatrists. It sets out a number of key objectives for service delivery: the promotion of domiciliary, day and respite services enabling people to live in their own homes "whenever possible"; making practical support for carers a high priority; placing assessment of need and good case management as the "cornerstone of high quality care"; promoting the development of a "flourishing independent sector", and so enhancing consumer choice; clarifying the responsibilities of agencies; and ensuring better value for money by the introduction of a new funding structure for social care. This paper provides a critical account of the policy and a personal review of its likely impact.

\section{Identifying responsibilities}

In contrast with the Audit Commission (1986) recommendations, the White Paper stipulates a uniform organisational framework for community services to the elderly, the mentally and physically handicapped and the mentally ill. Local authorities are given the lead responsibility for the provision of community

* A version of this paper was presented to a conference on 'Mental Health in the Community' held at the University of Surrey, Guildford on 21 March 1990. care. "Social services authorities" are to act as "arrangers and purchasers of care services rather than as monopolistic providers". This reflects the purchaser/provider distinction that lies at the heart of Working for Patients (Department of Health, 1989b).

One of the key concepts introduced in Caring for People is the distinction between "health" and "social" care. Puzzling in the context of a district nurse bathing an elderly person, it becomes incomprehensible when applied to the manifold needs of the chronically mentally ill. The traditional mental hospital had many 'latent' functions in meeting the social needs of its residents. Planners and providers of community-based services for the chronically mentally ill have also taken this range of needs into account. This has often been by setting up consortia to provide social care that continue to have significant input from health authority staff. The importance of the interaction between the 'clinical' (symptoms, behavioural disturbance and social functioning) and the 'social' (personal resources, social and interpersonal environment and life stresses) is, of course, central to contemporary psychiatric thought.

Local authority social service departments acting as "gatekeepers" to "social care" are to become responsible for the assessment of "social need" and the development of individual "care packages" to meet these needs. The nature of these assessments is outlined in a programmatic fashion, with a promise to issue detailed guidance to local authorities some four months before the assessment procedure is to be implemented. Detailed structured assessment of need was a central component in the Kent and Gateshead community care schemes for the elderly (Challis et al, 1988). In Britain there has been no similar relevant experience in assessment of the needs of the mentally ill in the context of a case management system, although there is a service-oriented 'needs assessment' literature which might offer a framework. The assessment of need is portrayed as an activity that can be carried out at one point in time (prior to discharge from psychiatric hospital). Mentally ill people, however, have changing needs, which in certain circumstances can only be properly understood by working with the patient or client for a prolonged period of time. 


\section{Case management}

Central to the provision of services is the system of "case management". The proposed core roles of the case manager include the identification of people in need; assessment of care needs; planning and securing the delivery of care; monitoring the quality of care; and reviewing client needs. This bureaucratic concept of case management, which stems from experience in pilot projects involving the elderly and mentally handicapped, also includes some devolution of budgetary management. The case manager will be able to draw upon the "mixed economy" of care, in which private and voluntary service providers compete with the statutory sector, although to date the budgetary flexibility provided to case managers has largely been limited to paying for non-professional carers (Challis et al, 1988).

A number of requirements have been identified for the successful operation of a case management system. These include clear definition of the client group, specification of the range of options on which the case manager might draw to develop a package of care and his or her span of authority over service providers, identification of the required skills and case load to be operated and precise location of the case manager on the "care pathway" (Davies, 1988). If these conditions are met there may be opportunities for "input mix economies" (that is making sure that the right range of appropriately priced services reach the right people): this may result in a shift from institutionally-oriented care towards community services.

A major research project is currently under way into case management for the mentally ill (Clifford \& Craig, 1988). The imposition of an interesting but untested case management system before results of this project are known is cause for severe concern. Although case management is a feature of services in America, evidence for its efficacy is equivocal. There is in any case little evidence that the necessary conditions outlined above operate in the context of existing mental illness services, minimising the likelihood of any theoretical gains in efficiency being achieved in practice. It is probable that precious resources will be syphoned off to pay for case managers who will have little direct client contact, so diminishing front-line services and further demoralising direct care staff. This is despite evidence from community care experiments that the direct involvement of case managers in providing support to their elderly clients and therefore improving morale (the "Heineken effect") is as important as the technical process of matching resources to needs (the "matching process")(Davies, 1988). Successful studies involving the community care of the mentally ill have also required a high degree of direct contact between case manager or support team and the client/patient. Close relationships are also necessary between the community team and the residual in-patient service. There is, in any case, a lack of clarity about what will in practice constitute the "mixed economy of care" for the mentally ill within a given catchment area, the concept depending on current experience with residential care for the elderly and its alternatives.

\section{Residential care}

Caring for People acknowledges the housing needs of those in receipt of community care, although there is no specific provision for the development of supported housing for the mentally ill and no discussion of the role of local housing authorities. Lack of supported housing is a major cause of pressure on psychiatric in-patient units, at least within the inner city. Local authorities are to assume responsibility "in collaboration with health care professionals for assessing the needs of new applicants for public support to residential or nursing home care", and subsequent placement. New funding arrangements will require social services authorities to negotiate contracts with 'independent' providers of residential care, with specific incentives towards running down their own provision, which will not be able to attract social security monies.

The role of the local authority sector in the provision of services to people with particularly challenging behaviour or high levels of dependency is acknowledged. In general, however, social service departments have limited experience of the residential care needs of younger people with mental illness, many of whom oscillate between acute psychiatric wards and unsatisfactory accommodation for the homeless.

Services are to be governed by contractual arrangements between purchaser and provider, analogous to the planned relationship between health authorities and hospitals (Department of Health, 1989b). Local authorities are to set up independent inspectorates to monitor the quality of residential care. American experience of the use of the private residential sector suggests that inspectorates are not an effective method of maintaining high quality care (Brown, 1985). Private sector providers tend to ignore public monitoring. There are severe problems in traditional approaches to regulation and contract compliance: the purchaser of services will need to adopt a consultative approach to the provider if quality is to be maintained. Although 'Purchase of Service Contracting' may result in short-run savings there are grounds for doubting the long-term cost advantages (Knapp, 1988), particularly as the private and voluntary sectors take on more difficult clients. 


\section{The role of the Health Service}

District health authorities are to be responsible for the provision of health (as opposed to social) care, acting through their directly managed units or in contract with other DHAs, the NHS Trusts, the private sector and other agencies. Discharge procedures will have to be agreed with the local authority, involving a "care programme" approach in which needs for health and social care are assessed prior to discharge and a named individual is made responsible for ensuring that these are met. The draft discharge procedure produced by the Royal College of Psychiatrists envisages a multidisciplinary and multiagency meeting being held prior to discharge at which hospital and community carers would set out their future involvement. It is not clear to whom this procedure will apply. The practicality of the procedure is open to doubt in inner-urban acute units running at high levels of occupancy where lengths of stay are short and precipitate discharges may be necessary to enable statutory responsibilities under the Mental Health Act to be carried out. Surprisingly, the discharge provision is seen by some senior social services officers as undermining the lead role of the local authority. Registers of vulnerable patients are to be kept, although the criteria for inclusion on the register are unclear. There is evidence of an overconcentration on people admitted to hospital: in reality the needs of those who are managed in the community are just as pressing.

The health authority will ensure that "health experts" are available to participate in assessment procedures, on a contractual basis. Community psychiatric nurses may also operate as "key workers" once a package of care is agreed. The pivotal role of the general practitioner in community care is explicitly acknowledged in Caring for People, although no specific initiatives relevant to the mentally ill are identified. The role of GPs is frequently overlooked in the community care literature, despite the epidemiological evidence that the vast majority of psychiatric morbidity receiving treatment is managed in primary health care settings. The relationship between GPs and evolving community-based services does not receive adequate attention, while the existence of the excellent British network of primary care brings into question the applicability of a Community Mental Health Centre movement to Britain.

The NHS will also be expected to provide "continuous residential health care" (alongside the private nursing home sector). Quite what the boundary between residential "health" and "social" care might be is unclear. There is considerable evidence that many people in receipt of long-term hospital care can be managed in non-hospital settings (Brown, 1985), but equally strong evidence that such patients experi- ence high degrees of psychiatric morbidity and considerable physical disability (Curson et al, 1988). Turf wars can confidently be predicted between the health service and social care agencies over who is responsible for what (or, more realistically, who will have to meet particular needs from their cash-limited budget). This in turn is likely to produce strains on those seeking to get help from health and local authorities: the patients, their families and GPs. Movement of long-stay patients out of hospitals into community settings is to result in transfer of resources from health to social services. This must be a cause of concern until the capacity and willingness of social service authorities to provide comprehensive care has been demonstrated.

\section{Planning and quality assurance}

Local authorities will be required to set out objectives and priorities, which should inform each individual assessment, in a "Community Care Plan". This will include an assessment of the needs of the local population, a statement of the authority's strategic objectives, and details of the assessment and case management procedures adopted. The source from which local authorities will obtain the necessary epidemiological expertise to produce this plan is unclear. Neither are we told the conceptual framework towards mental illness/mental distress/mental health that should be adopted to inform the plan. Complementary Health Authority plans will also have to be developed, although no structure to coordinate planning is proposed, the Government choosing to "concentrate on outcomes rather than machinery".

The purchaser/provider distinction would appear to bar service providers from any involvement in the planning process, a weakness also apparent in the NHS White Paper Working for Patients (Department of Health, 1989b). Presumably providers, including the voluntary sector, are expected to innovate 'at risk' and seek contracts from the purchaser. It has also been suggested that case managers might act as "visible and invisible hands for guiding resource allocation and policy development in the system" (Davies, 1988). Quite how this abstract notion fits in with the day-to-day realities of service management and planning is unclear, particularly when resource allocation rests on political rather than technical deliberations taking place at the levels of both central and local government.

The potential disjunction between service providers and the planning process is of grave concern, and will particularly affect the contribution of those professions such as medicine where historically involvement in planning and management has gone along with continuing front-line work. This appears to be a process of 'disempowerment' and may, as 
in America, lead to a demedicalisation and deprofessionalisation of community mental health services (Becker \& Schulberg, 1976; Brown, 1985, ch 3). The fragmentation of the service systems may then be increased by the withdrawal of medically trained staff to the hospitals. This will in turn negate any positive effects a case management system might have on improving other aspects of the coordination of care.

Caring for People puts a welcome emphasis on quality assurance and service monitoring, although some proposals, such as the development of inspectorates, may be surprisingly ineffective. Evaluative studies will be important in shaping the future development of community care, although adequate attention must be paid to the problems of generalising from experiment to everyday practice.

\section{Staffing the new services}

The importance of training for the new services is recognised, and opportunities for multidisciplinary training receive encouragement. However, Caring for People does not go near to setting out a training strategy for community care, or even provide the framework around which such a strategy could be built. It is likely that increased attention will have to be paid to the needs of staff, particularly those working within dispersed community-based services. Key policy issues will have to be resolved, notably whether multidisciplinary teamwork can be adapted for these new services or a new breed of professionals will be required to act as generic community mental health workers.

It will be necessary to help staff who deal regularly with chronically-disabled patients/clients to avoid 'burnout', and to prevent the 'upmarketing' that so frequently assails community-based mental health services. Managers must adopt new styles of working, developing skills in data collection, monitoring, quality assurance, supervision and support that have not previously been very apparent in mental health services. The interlinked issues of training, supervision, recruitment and retention of staff will come to the fore. Demographic changes and an increasingly competitive labour market are likely to result in increasing reliance on non-professionals as service providers. This trend is already apparent in the successful community care schemes for the frail elderly (Challis et al, 1988) and in emerging supported housing schemes for the chronically mentally ill.

\section{Funding services}

The system for the funding of "social care" is to be revised. Monies from a variety of sources, including income support, and housing benefit, that currently finance residential care will be brought under a single budget managed by the local authorities. This will be used to fund all aspects of "social care" for local residents. "Social care" will also include existing domiciliary, day care and respite services. The care element of the hostel deficit grant is also to be incorporated into this budget, leaving the housing corporation to disburse a special-needs housing management allowance for housing management alone. Funds will be paid through the revenue support grant and distributed according to the standard spending assessment for the personal social services. There will be no ring-fencing, and the SSA will reflect the perception of the Department of the Environment of the needs of the locality. Levels of psychiatric morbidity appear to vary sharply between areas, with socioeconomic deprivation a major factor. It is by no means certain that these variations will be adequately accounted for within the SSA. It is even less certain that notional community care monies will reach the mentally ill. Health authority monies will likewise not be ring-fenced.

A central fund, administered by regional health authorities, will provide grants for the development of social care for the mentally ill on the basis of joint plans between health and local authorities. This initiative is intended to act as an incentive for practical joint planning. Residents in areas where such planning does not take place will therefore be deprived of these grants, which will be made available to the population of districts where health and social service authorities are able to cooperate. The amount of money available is unspecified and the criteria governing its distribution are unclear. However, the fund offers regional health authorities the opportunity to shape community care for the mentally ill in a positive fashion. One option might be for such monies to be channelled into service-providing consortia in which the interests and expertise of a range of 'stakeholders', including health service professionals, could be harnessed. Such consortia have been proposed not only for mental health services but also to overcome the fragmentation of services for the elderly frail and the physically disabled (Audit Commission, 1986). If the 'case management' function in relation to the mentally ill were delegated by the local authority to a consortium, exciting new possibilities might emerge for rational, effective and efficient planning of community psychiatric care at a local level.

It is, however, difficult to reconcile the financial arrangements outlined in Caring for People with principles of equity. Increasing differences in the standard of care available across the country to the mentally ill, particularly those with chronic disorders, are likely to result unless direction from the centre, presumably organised through the Social Services Inspectorate, is much more effective in the future than it has proven hitherto. 


\section{Conclusion}

Prior to the publication of Caring for People and Working for Patients, mental health services were on the brink of exciting advances. Practical experience and further research would have led to clarification of the value of elements in the service system which are currently ill-understood, including the status of day care and sheltered work. Increasing understanding of the needs of carers would have resulted in a decrease in family suffering, and probably an improved prognosis for some major mental illnesses. Innovative supported housing schemes would have flourished, with the more general adoption of methods to support younger disabled residents in the dispersed housing that they demand. Multidisciplinary community teams specifically targeting the needs of the chronically mentally ill would probably have become the norm. A consensus about the future shape of mental health services was emerging. Caring for People over-rides this consensus. It imposes both innovative service solutions that have been shown to work in small-scale demonstration projects with a different community care client group and major organisational changes that appear to be based on ideology rather than evidence. It seems unlikely that, in general, local authorities will meet the needs of the mentally ill, since this is not a political priority. American evidence suggests the devolution of budgetary control to the local level specifically discriminates against the mentally ill vis-a-vis the more politically favoured mental handicap services. Social service departments do not have the expertise in providing for the client group that could enable them to carry out the case management function, even if the model espoused in Caring for People turns out to be desirable. Doubts have also been expressed about their more general managerial capacity to implement Caring for People, particularly in view of the recent major change in child care legislation. Reliance on the "mixed economy of care" may well result in a decline in standards of public psychiatric care, as resources are diverted to the financially expedient private sector. Paradoxically, this may lead to an increase in institutionally-oriented approaches to care at the expense of community programmes, since these tend to attract the most central funds. Perverse incentives may return.

The future of services for the chronically mentally ill in Britain is very unclear. The impact of Caring for People must be closely monitored. The voice of the consumers of psychiatric services, which include both sufferers and carers, will become increasingly important. Professionals from both health and social service backgrounds need to work together and to make links with consumer groups. Service providers and consumers must form alliances and together make a clear case for an effective and responsive service system.

\section{References}

AUdit Commission (1986) Making a Reality of Community Care. London: HMSO.

BeCKer, A. \& Schulberg, H. C. (1976) Phasing out state hospitals - a psychiatric dilemma. New England Journal of Medicine, 294, 255-261.

Brown, P. (1985) The Transfer of Care: Psychiatric Deinstitutionalisation and its Aftermath. London: Routledge \& Kegan Paul.

Challis, D., Chessum, R., Chesterman, J., Luckett, R. \& Woods, B. (1988) Community care for the frail elderly. British Journal of Social Work, 18, Supplement, 13-42.

Clifford, P. \& Craig, T. (1988) Case management systems for the long-term mentally ill. A proposed inter-agency initiative. London: NUPRD.

Curson, D. A., Patel, M., Liddle, P. F. \& Barnes, T. R. E. (1988) Psychiatric morbidity of a long-stay hospital population with chronic schizophrenia and implications for future community care. British Medical Journal, 297, 817-822.

DAviEs, B. (1988) Review article: Making a reality of community care. British Journal of Social Work, 18, Supplement, 173-187.

Department of Health (1989a) Caring for People. London: HMSO.

(1989b) Working for Patients. London: HMSO.

KNAPP, M. (1988) Searching for efficiency in long-term care: deinstitutionalisation and privatisation. British Journal of Social Work, 18, Supplement, 151-171.

A full list of references is available from the author

See also pp 698-699. 